\title{
Predisposing factors to severe external root resorption associated to orthodontic treatment
}

\author{
Gracemia Vasconcelos Picanço1, Karina Maria Salvatore de Freitas², Rodrigo Hermont Cançado ${ }^{3}$, \\ Fabricio Pinelli Valarelli ${ }^{4}$, Paulo Roberto Barroso Picanço5 ${ }^{5}$ Camila Pontes Feijão ${ }^{6}$
}

Objective: The aim of this study was to evaluate predisposing factors among patients who developed moderate or severe external root resorption (Malmgren's grades 3 and 4), on the maxillary incisors, during fixed orthodontic treatment in the permanent dentition. Methods: Ninety-nine patients who underwent orthodontic treatment with fixed edgewise appliances were selected. Patients were divided into two groups: G1 - 50 patients with no root resorption or presenting only apical irregularities (Malmgren's grades 0 and 1 ) at the end of the treatment, with mean initial age of 16.79 years and mean treatment time of 3.21 years; G2 - 49 patients presenting moderate or severe root resorption (Malmgren's grades 3 and 4) at the end of treatment on the maxillary incisors, with mean initial age of 19.92 years and mean treatment time of 3.98 years. Periapical radiographs and lateral cephalograms were evaluated. Factors that could influence the occurrence of severe root resorption were also recorded. Statistical analysis included chi-square tests, Fisher's exact test and independent $t$ tests. Results: The results demonstrated significant difference between the groups for the variables: Extractions, initial degree of root resorption, root length and crown/ root ratio at the beginning, and cortical thickness of the alveolar bone. Conclusion: It can be concluded that: Presence of root resorption before the beginning of treatment, extractions, reduced root length, decreased crown/root ratio and thin alveolar bone represent risk factors for severe root resorption in maxillary incisors during orthodontic treatment.

Keywords: Root resorption. Tooth movement. Orthodontics.

Objetivo: avaliar os fatores comuns aos pacientes que desenvolveram reabsorção radicular externa moderada ou severa (graus 3 e 4 de Malmgren) nos incisivos superiores, durante o tratamento ortodôntico fixo na dentição permanente. Métodos: foram selecionados 99 pacientes que iniciaram o tratamento ortodôntico fixo com a técnica Edgewise. Os pacientes foram divididos em dois grupos: G1 - 50 pacientes que concluíram o tratamento com ausência de reabsorções radiculares ou apresentando apenas irregularidades apicais (graus 0 e 1 de Malmgren), com idade média inicial de 16,79 anos e tempo de tratamento médio de 3,21 anos; G2 - 49 pacientes que finalizaram o tratamento apresentando reabsorção radicular moderada ou severa (graus 3 e 4 de Malmgren) nos incisivos superiores, com idade média inicial de 19,92 anos e tempo de tratamento médio de 3,98 anos. As radiografias periapicais e telerradiografias foram avaliadas, além de diversos fatores que pudessem influenciar a ocorrência de uma reabsorção severa. A análise estatística incluiu o testes qui-quadrado, teste exato de Fisher e teste $t$ independente. Resultados: foi demonstrada a presença de diferença significativa entre os grupos para as variáveis realização de extrações, grau de reabsorção radicular inicial, comprimento radicular, proporção coroa/raiz e da espessura da cortical óssea alveolar. Conclusão: pode-se concluir que são fatores de risco para reabsorção radicular severa nos incisivos superiores, durante o tratamento ortodôntico, a presença de reabsorção radicular antes do início do tratamento, a realização de extrações, o comprimento radicular reduzido, a proporção coroa/raiz diminuída e a espessura óssea alveolar fina.

Palavras-chave: Reabsorção radicular. Movimentação dentária. Ortodontia.

${ }^{1} \mathrm{MSc}$ in Orthodontics, UNINGA.

${ }^{2}$ Post-Doc in Orthodontics, UNINGÁ.

${ }^{3} \mathrm{PhD}$ in Orthodontics, FOB-USP.

${ }^{4} \mathrm{PhD}$ in Orthodontics, UNINGÁ.

${ }^{5} \mathrm{MSc}$ in Orthodontics, UNINGÁ.

${ }^{6}$ Specialist in Orthodontics, UVA-CE.

" The authors report no commercial, proprietary or financial interest in the products or companies described in this article.
How to cite this article: Picanço GV, Freitas KMS, Cançado RH, Valarelli FP, Picanço PRB, Feijão CP. Predisposing factors to severe external root resorption associated to orthodontic treatment. Dental Press J Orthod. 2013 Jan-Feb; 18(1):110-20 .

Submitted: June 04, 2010 - Revised and accepted: May 03, 2011

Contact address: Karina Maria Salvatore de Freitas

Rua Jamil Gebara, 1-25 - Apto 111 - Brazil

CEP: 17017-150 - Bauru/SP - E-mail: kms@@uol.com.br 


\section{INTRODUCTION}

The external root resorption (ERR) is frequently observed by orthodontists and are usually diagnosed in clinical practice when radiographs (panoramic or periapical) are performed. ERR are usually asymptomatic, and when the loss of root structure by resorption become severe the physiology and retention of the affected teeth may be compromised. ${ }^{14}$

The anterior teeth are more affected by root resorption, probably because they are single-rooted with tapered roots, conducting the orthodontic force directly to the apex. They are also constantly moved during orthodontic treatment. Moreover, they are more exposed to external factors, such as trauma, making these teeth a good reference for the magnitude of root resorption during orthodontic treatments. ${ }^{22}$

The literature about root resorption is extensive but very controversial in relation to the factors that actually influence the occurrence and severity of resorption during orthodontic treatment. In this context, this study was conducted in order to evaluate which factors are commonly observed in patients who develop moderate or severe degrees of resorption in maxillary incisors during orthodontic treatment.

\section{MATERIAL AND METHODS Material}

The sample consisted of 99 patients from the Paulo Picanço Advanced Orthodontics Center, Fortaleza-CE, who underwent orthodontic treatment with fixed appliance (Edgewise technique) in the permanent dentition, and met the following requirements: Good oral and systemic health, no tooth loss in the region from canine to canine in the maxillary arch, absence of vertical bone loss and periodontal disease, and no prosthesis. Patients who developed grade 2 resorption ${ }^{26}$ at the end of treatment was excluded from the study. Only patients who had complete treatment records, medical records, initial cephalogram and initial and final periapical radiographs of maxillary incisors in good conditions were included in the sample.

Teeth with endodontic treatment, incomplete development of the root apex, tooth agenesis, supernumerary teeth and patients with incomplete initial records were excluded from the sample. Radiographs with distortion or blur were also eliminated.

\section{Sample division:}

" Group 1 (Patients who had degree 0 or 1 of root resorption of the maxillary incisors at the end of treatment): 50 patients, 26 without and 24 with extractions (13 first premolars; 8 second premolars and 3 first molars). The mean age at the beginning of the treatment was 16.79 years, the mean age at the end of treatment was 20.00 years. The mean treatment time was 3.21 years.

" Group 2 (patients who had degree 3 or 4 of root resorption in maxillary incisors at the end of treatment): 49 patients, 26 without and 24 with extractions (31 first premolars, 9 second premolars, 2 first molars) The mean age at the beginning of the treatment was 19.92 years and the mean age at the end of treatment was 23.90 years. The mean treatment time was 3.98 years.

\section{Methods}

In order to evaluate the variables, initial and final periapical radiographs and initial cephalograms were used of each patient. The radiographs were scanned with a scanner (Microtek ScanMaker i800, Microtek International, Inc., Carson, USA) and coupled to a Pentium computer. The images were transferred to the software Dolphin Imaging Premium 10.5 (Dolphin Imaging \& Management Solutions, Chatsworth, USA) through which the images were digitized, the points were marked and cephalometric measurements were performed automatically by the software Dolphin.

The periapical radiographs were analyzed as follows: The degree of initial and final, based on the classification proposed by Malmgren: Grade 0 (no resorption), grade 1 (presence of apical irregularities), grade 2 (presence of resorption by $2 \mathrm{~mm}$ ), grade 3 (presence of resorption between $2 \mathrm{~mm}$ and a third of the original length), grade 4 (the presence of root resorption greater than one third of the original length of the root) (Fig 1). ${ }^{7,8}$

The bone crest was classified based on the observation of periapical radiographs as follows: Flat (width greater than $1 \mathrm{~mm}$, representing the crest of a rectangular shape) and sharp (width less than or equal to $1 \mathrm{~mm}$, representing the crest of triangular shape) (Fig 2). 
The evaluation of the root shape was performed based on the classification proposed by Consolaro ${ }^{9}$ as follows: Triangular $(\mathrm{T})$, rhomboid $(\mathrm{R})$, pipette $(\mathrm{P})$ and dilacerated (D) (Fig 3).

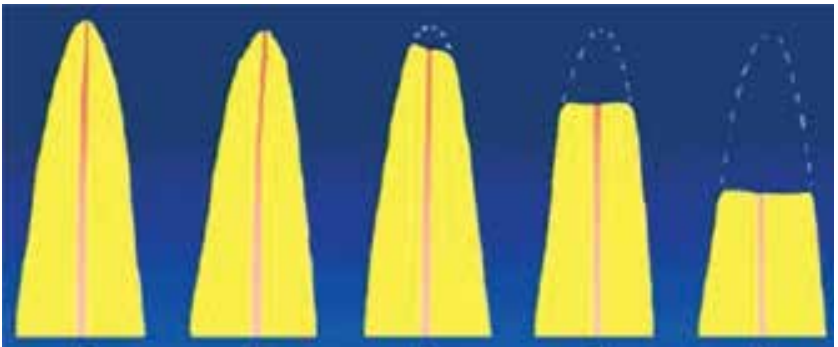

Figure 1 - Malmgren ${ }^{7,8}$ classification
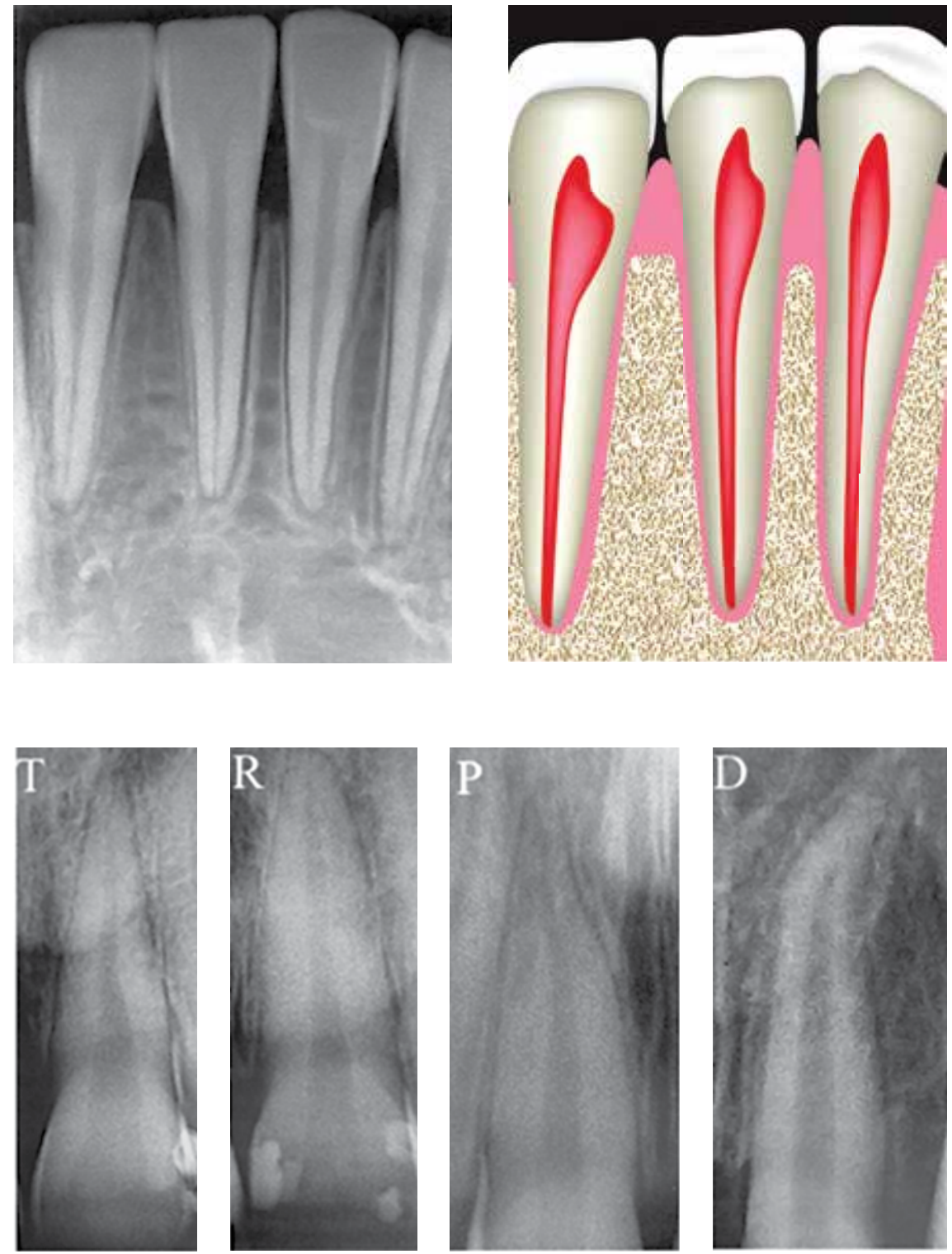

Figure 3 - Root morphologies: triangular (T), rhomboid (R), pipette (P) and dilacerated (D). 


\section{Root/crown proportion}

Example of Grade 4

Crown: $11 \mathrm{~mm}$

Root: $10 \mathrm{~mm}$

$11----100 \%$

$10----X$

$X=0.9$

Proportion $=1: 0.9$

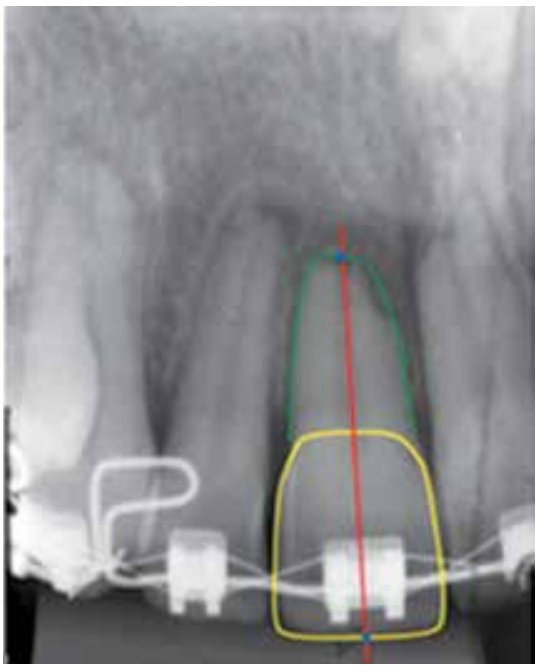

Figure 4 - Evaluation of the crown/root proportion.

error and Dahlberg ${ }^{11}$ formula to estimate the random error. To evaluate the error of the score of root resorption, the Kappa test was used.

\section{Statistical analysis}

It was used the following statistical tests: Chisquare test for intergroup comparison of gender, type of malocclusion, treatment with or without extraction, shape of the root and bone crest; independent $t$ test for comparison of the ages, treatment time and cephalometric variables between the two groups. All tests were performed with Statistica software (Statistica for Windows, versão 7.0, Statsoft). Results were considered significant when $\mathrm{p}<0.05$.

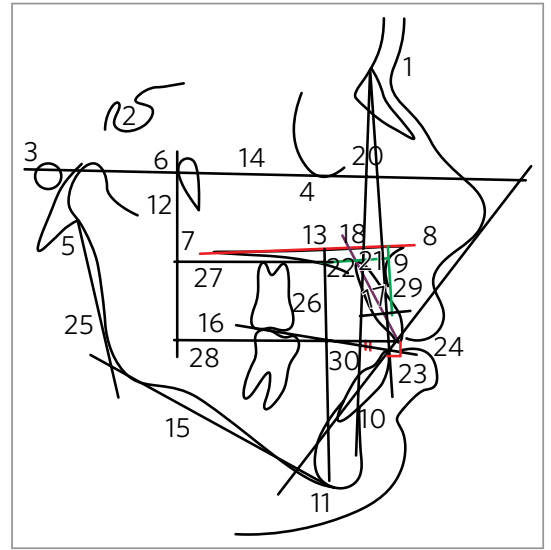

Figure 5 - Cephalometric variables used.

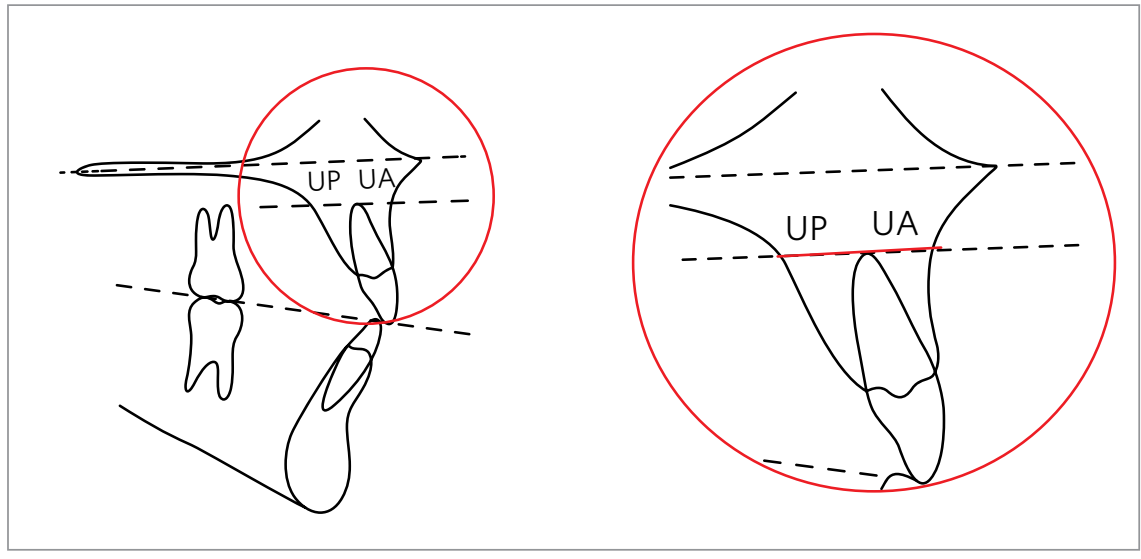

Figure 6 - UA+UP distance, parallel to the palatal plane (ANS-PNS). 

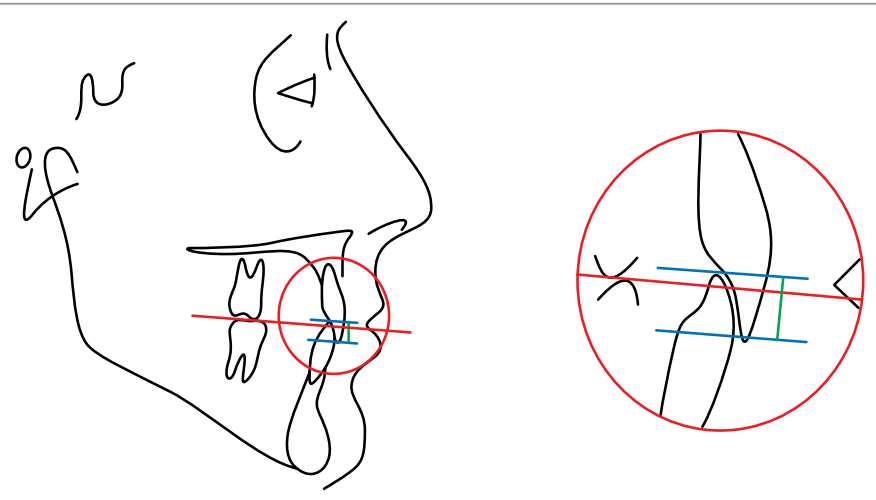

Figure 7 - Overbite.
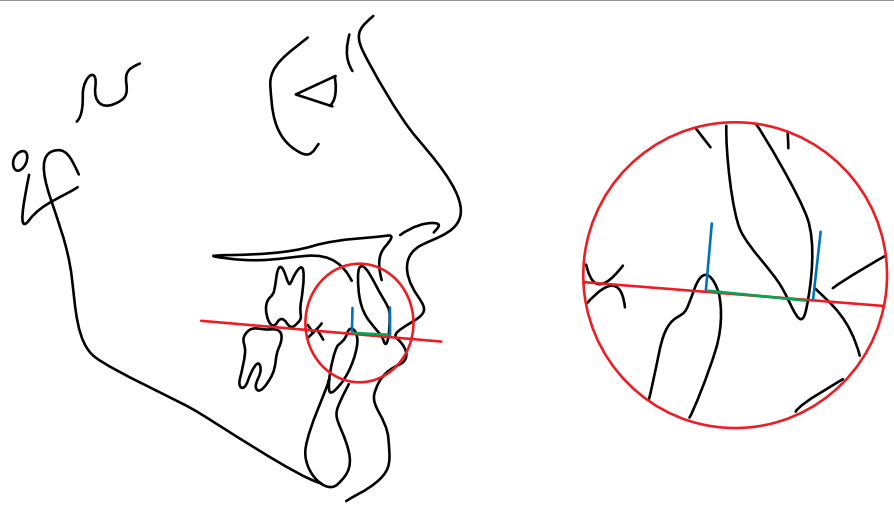

Figure 8 - Overjet

Table 1 - Cephalometric variables used.

\begin{tabular}{|c|c|}
\hline 1-PTV INC (mm) & Distance of the incisal of the maxillary central incisor to the PTV line (line vertical to the pterygoid fossa, perpendicular to Frankfurt). \\
\hline 1-PTV APIC (mm) & Distance of the apical root of the maxillary central incisor to the PTV line (line vertical to the pterygoid fossa, perpendicular to Frankfurt). \\
\hline 1.NA (degrees) & Angle between the long axis of the maxillary central incisor and the line NA. \\
\hline FMA (degrees) & Angle formed by the horizontal planes of Frankfurt and mandibular (GoMe) \\
\hline $\mathrm{PFH} / \mathrm{AFH}(\mathrm{mm})$ & Proportion between the posterior face height (S-Go) and the anterior face height (N-Me). \\
\hline ANB (degrees) & Angle formed by the lines NA and NB. \\
\hline Wits $(\mathrm{mm})$ & Distance between the points A and B projected perpendicularly to the functional occlusal plane. \\
\hline Overjet (mm) & Distance between the incisal edges of the maxillary and mandibular central incisors projected perpendicularly to the occlusal plane. \\
\hline Overbite $(\mathrm{mm})$ & Distance between the incisal edges of the maxillary and mandibular central incisors measured perpendicularly to the occlusal plane. \\
\hline $\mathrm{H}-11(\mathrm{~mm})$ & Total length of the maxillary central incisor, including crown and root. \\
\hline $\mathrm{UA}+\mathrm{UP}(\mathrm{mm})$ & Sum of the thickness of the anterior (buccal) and posterior (palatal) alveolar crest bone. \\
\hline
\end{tabular}

\section{RESULTS}

The largest linear random error found, was for the variable 1-PTV apical $(1.36 \mathrm{~mm})$, and angular for the measure 1.NA $\left(1.41^{\circ}\right)$ and the largest systematic error was $0.12 \mathrm{~mm}$ of the variable Overjet. The percentage of agreement was substantial (87\%) and Kappa coefficient was 0.794 .

Increased age and longer treatment was significantly related to the occurrence of severe root resorption (Table 2).

Gender, type of malocclusion, morphology of the root and the bone crest are not risk factors for developing severe root resorption (Table 3). The treatment protocol with extractions increases the risk of severe apical root resorption (Table 3).

The short root length and the decreased proportion of the crown/root ratio at the beginning of treatment increases the chance of developing severe resorption (Table 4).

Patients with thin maxillary alveolar cortical bone are more likely to develop severe resorption than patients with good bone thickness (Table 5). 
Table 2 - Intergroup comparison of the ages and treatment time (independent $t$ test)

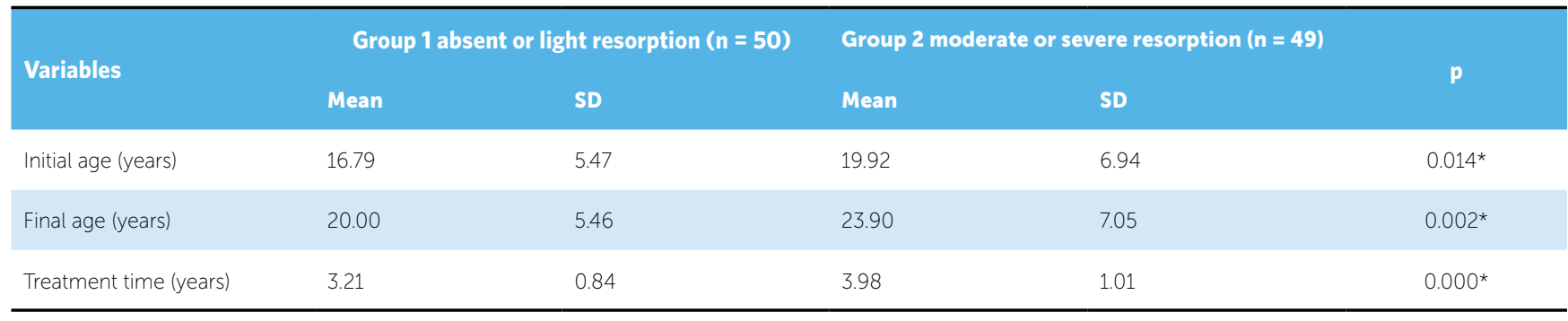

* Statistically significant $p<0.05$

Table 3 - Intergroup comparison of the gender, type of malocclusion, root morphology, alveolar crest and presence of initial resorption (chi-square).

\begin{tabular}{|c|c|c|c|c|c|c|}
\hline Variables & & $\begin{array}{l}\text { Group } 1 \text { absent or light } \\
\text { resorption }(n=50)\end{array}$ & $\begin{array}{l}\text { Group } 2 \text { moderate or } \\
\text { severe resorption }(n=49)\end{array}$ & $\lambda$ & DF & $\mathbf{p}$ \\
\hline Gender & $\begin{array}{l}\text { Male } \\
\text { Female }\end{array}$ & $\begin{array}{l}18.18 \% \\
32.32 \%\end{array}$ & $\begin{array}{l}13.13 \% \\
36.36 \%\end{array}$ & 1.03 & 1 & 0.309 \\
\hline Malocclusion & $\begin{array}{l}\text { Class I } \\
\text { Class II } \\
\text { Class III }\end{array}$ & $\begin{array}{l}8.08 \% \\
29.29 \% \\
13.13 \%\end{array}$ & $\begin{array}{l}12.12 \% \\
31.31 \% \\
6.06 \%\end{array}$ & 3.45 & 2 & 0.179 \\
\hline $\begin{array}{l}\text { Type of } \\
\text { treatment }\end{array}$ & $\begin{array}{l}\text { Without extraction } \\
\text { With extraction }\end{array}$ & $\begin{array}{l}26.26 \% \\
24.24 \%\end{array}$ & $\begin{array}{l}9.09 \% \\
40.40 \%\end{array}$ & 2.24 & 1 & $0.000 *$ \\
\hline $\begin{array}{l}\text { Root } \\
\text { morphology }\end{array}$ & $\begin{array}{l}\text { Triangular } \\
\text { Rhomboid } \\
\text { Pipette } \\
\text { Dilacerated }\end{array}$ & $\begin{array}{l}4.04 \% \\
34.34 \% \\
10.10 \% \\
2.02 \%\end{array}$ & $\begin{array}{l}4.04 \% \\
29.29 \% \\
13.13 \% \\
3.03 \%\end{array}$ & 0.97 & 3 & 0.806 \\
\hline Alveolar crest & $\begin{array}{l}\text { Flat } \\
\text { Sharp }\end{array}$ & $\begin{array}{l}29.29 \% \\
21.21 \%\end{array}$ & $\begin{array}{l}35.35 \% \\
14.14 \%\end{array}$ & 1.95 & 1 & 0.162 \\
\hline $\begin{array}{l}\text { Initial degree of } \\
\text { resorption }\end{array}$ & $\begin{array}{l}0 \\
1\end{array}$ & $\begin{array}{l}48.48 \% \\
2,02 \%\end{array}$ & $\begin{array}{l}30.30 \% \\
19,19 \%\end{array}$ & 17.91 & 1 & 0.000 * \\
\hline
\end{tabular}

* Statistically significant $p<0.05$

Table 4 - Intergroup comparison of the root length and the crown/root proportion in $T_{1}, T_{2}$ and $T_{2}-T_{1}$ (independent $t$ test)

\begin{tabular}{|c|c|c|c|c|c|}
\hline \multirow{2}{*}{ Variables } & \multicolumn{2}{|c|}{ Group 1 absent or light resorption $(n=50)$} & \multicolumn{2}{|c|}{ Group 2 moderate or severe resorption ( $n=49$ ) } & \multirow{2}{*}{$\mathbf{p}$} \\
\hline & Mean & SD & Mean & SD & \\
\hline Root length $T_{1}(\mathrm{~mm})$ & 16.69 & 2.06 & 15.90 & 1.58 & $0.033^{*}$ \\
\hline Root length $T_{2}(\mathrm{~mm})$ & 16.05 & 2.04 & 12.44 & 1.74 & $0.000 *$ \\
\hline Root length $T_{2}-T_{1}$ & -0.64 & 0.49 & -3.45 & 1.40 & $0.000 *$ \\
\hline Crown/root Initial proportion & $1: 1.82$ & 0.24 & $1: 1.69$ & 0.21 & $0.005^{\star}$ \\
\hline Crown/root Final proportion & $1: 1.78$ & 0.24 & $1: 1.37$ & 0.20 & $0.000 *$ \\
\hline Crown/root $T_{2}-T_{1}$ & -0.03 & 0.04 & -0.31 & 0.15 & $0.000 *$ \\
\hline
\end{tabular}

* Statistically significant $p<0.05$ 
Table 5 - Intergroup comparison of the cephalometric variables (independent $t$ test).

\begin{tabular}{|c|c|c|c|c|c|}
\hline \multirow{2}{*}{ VARIABLES } & \multicolumn{2}{|c|}{ Group 1 absent or light resorption ( $n=50$ ) } & \multicolumn{2}{|c|}{ Group 2 moderate or severe resorption $(n=49)$} & \multirow{2}{*}{$\mathbf{p}$} \\
\hline & Mean & SD & Mean & SD & \\
\hline 1-PTV INC (mm) & 59.83 & 5.96 & 61.84 & 5.01 & 0.073 \\
\hline 1-PTV APIC (mm) & 49.65 & 7.76 & 51.15 & 3.66 & 0.224 \\
\hline 1.NA (degrees) & 26.68 & 8.98 & 29.73 & 6.84 & 0.060 \\
\hline FMA (degrees) & 27.36 & 7.45 & 26.29 & 6.07 & 0.438 \\
\hline $\mathrm{PFH} / \mathrm{AFH}(\mathrm{mm})$ & 0.72 & 0.11 & 0.74 & 0.11 & 0.378 \\
\hline ANB (degree) & 2.20 & 2.27 & 2.54 & 2.11 & 0.441 \\
\hline Wits (mm) & -1.03 & 10.67 & -0.81 & 5.43 & 0.900 \\
\hline Overjet (mm) & 1.14 & 1.48 & 2.53 & 5.68 & 0.097 \\
\hline Overbite (mm) & 3.43 & 2.52 & 4.17 & 4.48 & 0.315 \\
\hline $\mathrm{H}-11$ (mm) & 20.04 & 3.15 & 20.23 & 4.61 & 0.810 \\
\hline $\mathrm{UA}+\mathrm{UP}(\mathrm{mm})$ & 14.26 & 4.65 & 12.31 & 3.02 & $0.015^{*}$ \\
\hline
\end{tabular}

* Statistically significant $p<0.05$.

\section{DISCUSSION}

Sample

The sample of this study was obtained from Paulo Picanço Orthodontics Center. Initially, periapical radiographs were examined to obtain the degree of resorption and then the patients were divided into two groups. At this time, it was excluded patients with absences in the region from canine to canine in the maxilla, presence of vertical bone loss, patients with resorption grade 2, patients with incomplete, damaged or without final orthodontic records. After the selection, 165 patients from all subjects had completed files available. After checking the periapical radiographs, the evaluation of the orthodontic records was made, noting that many patients had incomplete records, absence of final orthodontic records, lack of signed informed consent, incomplete permanent dentition. At the end, a final sample of 99 patients attended the inclusion criteria.

Although the control group (group 1, with resorption grade 0 or 1 at the end of treatment) have more patients, this was the most difficult to collect, especially patients with grade 0 who fulfilled all the requirements of research, since the literature affirms that the resorption in orthodontically treated patients is 100\%., 3, 19,22,36

To collect the ideal sample was the greatest challenge of this study, however, the number of subjects was considered good, because of the strict selection criteria.

\section{Method}

In this study only the maxillary incisors were evaluated, because previous studies showed that these teeth have more susceptibility to develop resorption during orthodontic treatment. Incisors are the more constantly moved, for example, during retraction and intrusion. ${ }^{8,12,22}$ Moreover, incisors are single-rooted elements and easier for obtaining images without distortion or image overlays. ${ }^{15,18,23,33}$

The most common radiographic examination used for the detection of resorption is periapical $\mathrm{x}-$ ray. For Sameshima and Asgarifar ${ }^{33}$ this type of radiograph shows finer detail, allowing visualization of anatomical details such as the cementoenamel junction and have less distortion and overlap when compared to panoramic and cephalometric radiographs. ${ }^{26}$ In this study the standardized technique for periapical radiographs used was the parallelism, and the fact that all patients in the study underwent radiographic follow-up at the Paulo Picanço Orthodontics Center, ensuring greater standardization of radiographs. The choice for this technique is the fact that it allows greater standardization of the image for pre- and post-treatment, what is not possible by the bisection technique, since the average angle of incidence of $\mathrm{x}$-rays is more difficult to reproduce even hindering over the accuracy of quantitative measurements. ${ }^{32}$ 
Age

The results were significant in relation to age, because the group 1 presented younger patients when compared to group 2. It can be affirmed that older patients have a higher risk of developing moderate or severe root resorption during orthodontic treatment (Table 2).

Some authors mentioned that age does not influence root resorption. ${ }^{1,9,19}$ However, corroborating the results of this study, Sameshima and Sinclair ${ }^{34,35} \mathrm{ob}-$ served that the resorption is most prevalent in adults than in children.

Adults seem more susceptible to resorption because, with aging, the periodontal membrane becomes less vascularized, inelastic, more narrow and the cementum becomes thicker, and also the fact that the apical third of the root is more firmly anchored in adult patients, creating a difficulty in tooth movement and predisposing to resorption. . $^{3,4}$

However, the results of this study must be interpreted with caution, since the age difference between the groups 1 and 2 was only about three years, and both patients in group 1 and group 2 were considered "young adults" (Table 2).

\section{Treatment time}

The results showed that a longer treatment is a risk factor to the occurrence of severe root resorption, as the group 1 showed a significantly shorter treatment time compared to group 2 (Table 2).

These results are opposite to those authors who suggest no relation between the duration of treatment and the degree of resorption. ${ }^{2,13,37}$

According to Sameshima and Sinclair, ${ }^{34,35}$ the duration of treatment and the amount of horizontal displacement of the apical root of the maxillary incisors had strong correlation with root resorption.

Brin et $\mathrm{al}^{5}$ evaluated the root resorption in patients with Class II malocclusion treated in only one phase or with treatment divided into two phases, observed that patients undergoing a single phase of treatment had a proportion of moderate to severe resorption slightly larger than the group with two phases of treatment.

\section{Gender}

In this study no significant relationships were found between severe resorption and the gender (Table 3), agreeing with the results of most authors. ${ }^{9,19,20,31,34,35,36}$

\section{Type of malocclusion}

Regarding the type of malocclusion and orthodontic techniques, many studies have shown that there is no relationship between root resorption and type of malocclusion. ${ }^{6,19,30}$ The results of this study also found no significant relationship (Table 3).

\section{Type of treatment (with or without extraction)}

The results of this study showed that patients treated with extraction were more likely to develop severe root resorption than patients whose treatment did not include extraction (Table 3).

Many studies showed that patients treated with extractions showed more resorption and with more severe degree, because mechanical retraction of anterior teeth cause greater movement of the root apex and the need for longer treatment. ${ }^{12,16,29,34,35}$

\section{Root and bone crest morphology}

The results of this study showed no relationship between the morphology of the root and the bone crest to the occurrence of severe resorption during orthodontic treatment (Table 3).

Most authors consider, regarding the root morphology, that teeth with atypical root have a higher risk of root resorption..$^{25,29,30,34,35}$

It is likely that this result is due to the fact that most of the sample presented rhomboid root and tapered bone crest, which according to most authors, reduce the risk of resorption.

\section{Degree of initial resorption}

The results have shown that patients with some degree of root resorption at the beginning of treatment have a greater predisposition and an increased risk of developing severe root resorption during orthodontic treatment (Table 3).

Some authors believe that patients with minimal or no resorption present little risk to severe resorption, patients with moderate resorption have regular risk to severe and extreme resorption, while patients starting orthodontic treatment with severe resorption has a high risk of extreme resorption at the end of treatment. ${ }^{6,36}$

\section{Root length and crown/root proportion}

In this study, the root length decreased significantly more during treatment in patients with severe 
resorption compared to the group with mild resorption (Table 4), as expected, because of the criterion for group division. However, the root length of group 2 was already smaller than the group 1 before the beginning of treatment (Table 4). This can be considered an indication that a smaller root length at the beginning of treatment is a risk factor for increased occurrence of root resorption during orthodontic treatment. Likewise, the crown/root proportion at the beginning of treatment was lower in group 2 than in group 1, and continued lower at the end of treatment (Table 4). Furthermore, the crown/ root proportion suffered a greater decrease in group 2 (Table 4), as expected.

The root length and crown/root proportion seem to influence the tendency to resorption. A large crown will tend to concentrate force on certain focal points, thus short roots tend to suffer more resorption during orthodontic movements.

In cases of patients with severe resorption the professional should be very careful with the root length, teeth with roots length less than or equal to $9 \mathrm{~mm}$ have a higher risk of teeth mobility. ${ }^{27}$ According to Kalkwarf et al, ${ }^{24}$ the reduction of $3 \mathrm{~mm}$ in apical tooth structure corresponds to the loss of alveolar bone crest of $1 \mathrm{~mm}$.

\section{Incisor position}

Variables related to the position of the maxillary incisor showed no statistically significant difference between the groups, indicating no relationship among the protrusion and buccal tipping of the incisors and the occurrence of severe root resorption (Table 5).

The results showed no statistically significant difference between the groups for the protrusion and initial inclination of the incisors, indicating that they are not risk factors to the occurrence of severe root resorption, although group 2 showed a greater buccal inclination of the incisors at the beginning of treatment, but not statistically significant (Table 5).

\section{FMA and PFH/AFH}

The FMA angle showed no statistically significant difference between the groups, indicating no relationship between the vertical pattern of the patients and the occurrence of severe root resorption (Table 5). The proportion PFH/AFH showed no statistically significant difference between the groups, indicating no relationship between the facial pattern of the patients and the occurrence of severe root resorption (Table 5).

Handelman ${ }^{17}$ analyzed the variable SN-MP that, represents the relationship between the cranial base and the mandibular plane and found positive association between this variable and root resorption.

Harris, Kineret and Tolley ${ }^{19}$ also conducted a study to evaluate the relationship between FMA and root resorption and found a relatively high correlation between them.

\section{ANB and WITS}

The results of this study demonstrate that the maxillomandibular relationship was not significantly different between the groups, indicating that this variable is not a risk factor for the occurrence of severe root resorption (Table 5). It is likely that this result is due to the fact that the present sample does not show large maxillomandibular discrepancies.

In a study by Harris, Kineret and Tolley ${ }^{19}$, these two variables (ANB and Wits) were evaluated and it was observed that both have strong relationship with the occurrence of resorption, as higher maxillomandibular discrepancies tend to require greater retraction of anterior teeth and therefore enhance the risk of resorption.

\section{Overjet and Overbite}

The results of this study showed no statistically significant difference between the groups for overjet and overbite, indicating that, at the beginning of treatment, these variables are not a risk factor to the occurrence of severe root resorption (Table 5). These findings, however, contradict most of the authors and the justification for this is the absence of great skeletal discrepancies and also the absence of a significant number of cases with open bite and/or deep bite.

There is a consensus in considering the overjet as a risk factor for resorption, because the correction requires the retraction of anterior teeth, and the greater the magnitude of this malocclusion, the greater the amount of movement, increasing the risk and severity of resorption. ${ }^{2,5,28,31}$ Freitas et $\mathrm{al}^{12} \mathrm{ob}-$ served a great degree of resorption for correction of great amount of overjet. 
$\mathrm{H}-11$

The results showed no significant difference between the groups for this variable, indicating that the position of the incisors in relation to the palatal plane at the beginning of treatment is not a risk factor for the occurrence of severe root resorption.

Some studies show that the intrusion with lingual torque movement, horizontal movement of the apex increase the chance of root resorption. ${ }^{1,10,30,31}$ For Parker and Harris, ${ }^{31}$ extrusion movements are also risk factors, but less aggressive than the intrusion. For Freitas et $\mathrm{al},{ }^{12}$ anteroposterior movement, is a risk factor found in $29 \%$ of the resorptions observed in patients during orthodontic treatment.

\section{Bone thickness}

The bone thickness (UA + UP) showed a statistically significant result (Table 5) confirming the authors hypothesis about the increased risk of resorption in patients with thin cortical. ${ }^{10,17}$
According to Handelman, ${ }^{17}$ the dimension of the alveolus (UA + UP) seems to set limits to orthodontic treatment and challenge these limits can accelerate iatrogenic fenestrations and root resorption. Horiuchi, Hotokezaka and Kobayashi ${ }^{21}$ observed that the proximity of the apex to the palatal cortex also influences the resorption. To these authors, the maxillary width insufficient to tooth movement can be considered a risk associated to root resorption.

\section{CONCLUSIONS}

According to the methodology applied and the conditions established in this study, it can be conclude that cases treated with extraction have a higher chance of presenting severe root resorption than patients treated without extractions. Short root length and crown/root proportion at the beginning of treatment increases the chance of developing severe resorption. Patients with thin cortical alveolar bone are more likely to develop severe resorption than patients with good bone thickness. 
1. Baumrind S, Korn EL, Boyd RL. Apical root resorption in orthodontically treated adults. Am J Orthod Dentofacial Orthop. 1996;110(3):311-20

2. Beck BW. Harris EF. Apical root resorption in orthodontically treated subjects analysis of edgewise and light wire mechanics. Am J Orthod Dentofacial Orthop. 1994;105(4):350-61.

3. Brezniak N, Wasserstein A. Root resorption after orthodontic treatment: Part 1. Literature review. Am J Orthod Dentofacial Orthop. 1993;103(1):62-6.

4. Brezniak N, Wasserstein A. Root resorption after orthodontic treatment: Part 2. Literature review. Am J Orthod Dentofacial Orthop. 1993;103(2):138-46.

5. Brin I, Tulloch JF, Koroluk L, Philips C. External apical root resorption in Class II malocclusion: a retrospective review of 1-versus 2-phase treatment. Am J Orthod Dentofacial Orthop. 2003:124(2):151-6

6. Capelozza Filho L, Silva Filho OG. Reabsorção radicular na clínica ortodôntica: atitudes para uma conduta preventiva. Rev Dental Press Ortod Ortop Facial. 1998:3(1):104-26.

7. Chiqueto K, Martins DR, Janson G. Effects of accentuated and reversed curve of Spee on apical root resorption. Am J Orthod Dentofacial Orthop. 2008;133(2):261-8

8. Chiqueto K. Influência da mecânica intrusiva de acentuação e reversão da curva de spee no grau de reabsorção radicular [dissertação]. Bauru (SP): Universidade de São Paulo; 2005

9. Consolaro A. Reabsorções dentárias nas especialidades clínicas. $2^{\text {a }}$ ed. Maringá: Dental Press; 2005.

10. Costopoulos G, Nanda R. An evaluation of root resorption incident to orthodontic intrusion. Am J Orthod Dentofacial Orthop. 1996:109(5):543-8.

11. Dahlberg G. Statistical methods for medical and biological students. London: George Allen and Unwin; 1940

12. de Freitas MR, Beltrão RT, Janson G, Henriques JF, Chiqueto K. Evaluation of root resorption after open bite treatment with and without extractions. Am J Orthod Dentofacial Orthop. 2007;132(2):143.e15-22.

13. Dermaut LR, De Munck A. Apical root resorption of upper incisors caused by intrusive tooth movement: a radiographic study. Am J Orthod Dentofacial Orthop. 1986;90(4):321-6.

14. Dudic A, Giannopoulou C, Leuzinger M, Kiliaridis S. Detection of apical root resorption after orthodontic treatment by using panoramic radiography and cone-beam computed tomography of super-high resolution. Am J Orthod Dentofacial Orthop. 2009:135(4):434-7.

15. Furquim LZ. Perfil endocrinológico de pacientes ortodônticos com e sem reabsorções dentárias: correlação com a morfologia radicular e da crista óssea. [tese]. Bauru (SP): Faculdade de Odontologia de Bauru; 2002

16. Gadben JMA, Ribeiro A, Generoso R, Armond MC, Marques LS. Avaliação radiográfica periapical dos níveis de reabsorção radicular de incisivos superiores após tratamento ortodôntico. Arq Odontol. 2006:42(4):257-336.

17. Handelman CS. The anterior alveolus: its importance in limiting orthodontic treatment and its influence on the occurrence of iatrogenic sequelae. Angle Orthod. 1996:66(2):95-109

18. Harris EF, Baker WC. Loss of root length and crestal bone height before and during treatment in adolescent and adult orthodontic patients. Am J Orthod Dentofacial Orthop. 1990;98(5):463-9.

19. Harris EF, Kineret SE, Tolley EA. A heritable component for external apical root resorption in patients treated orthodontically. Am J Orthod Dentofacial Orthop. 1997:111(3):301-9.
20. Hendrix I, Carels C, Kuijpers-Jagtman AM, Van 'T Hof M. A radiographic study of posterior apical root resorption in orthodontic patients. Am J Orthod Dentofacial Orthop. 1994;105(4):345-9.

21. Horiuchi A, Hotokezaka H, Kobayashi K. Correlation between cortical plate proximity and apical root resorption. Am J Orthod Dentofacial Orthop. 1998;114(3):311-8

22. Janson GR, De Luca Canto G, Martins DR, Henriques JF, De Freitas MR A radiographic comparison of apical root resorption after orthodontic treatment with 3 different fixed appliance techniques. Am J Orthod Dentofacial Orthop. 2000;118(3):262-73.

23. Kaley J, Phillips C. Factors related to root resorption in edgewise practice. Angle Orthod. 1991;61(2):125-32

24. Kalkwarf KL, Krejci RF, Pao YC. Effect of apical root resorption on periodontal support. J Prosthet Dent. 1986:56(3):317-9.

25. Kjaer I. Morphological characteristics of dentitions developing excessive root resorption during orthodontic treatment. Eur J Orthod. 1995:17(1):25-34.

26. Levander E, Malmgren $O$. Evaluation of the risk of root resorption during orthodontic treatment: a study of upper incisors. Eur J Orthod. 1988:10(1):30-8

27. Levander $E$, Malmgren $O$. Long-term follow-up of maxillary incisors with severe apical root resorption. Eur J Orthod. 2000:22(1):85-92.

28. Linge $L$, Linge $B O$. Patient characteristics and treatment variables associated with apical root resorption during orthodontic treatment. Am J Orthod Dentofacial Orthop. 1991;99(1):35-43

29. Marques LS, Ramos-Jorge ML, Rey AC, Armond MC, Ruellas AC. Severe root resorption in orthodontic patients treated with the edgewise method: Prevalence and predictive factors. Am J Orthod Dentofacial Orthop. 2010:137(3):384-8.

30. Mirabella AD, Artun J. Risk factors for apical root resorption of maxillary anterior teeth in adult orthodontic patients. Am J Orthod Dentofacia Orthop. 1995:108(1):48-55

31. Parker RJ, Harris EF. Directions of orthodontic tooth movements associated with external apical root resorption of the maxillary central incisor. Am J Orthod Dentofacial Orthop. 1998:114(6):677-83

32. Remington DN, Joondeph DR, Artun J, Riedel RA, Chapko MK. Long-term evaluation of root resorption occurring during orthodontic treatment. Am J Orthod Dentofacial Orthop. 1989:96(1):43-6.

33. Sameshima GT, Asgarifar K. O. Assessment of root resorption and root shape: periapical vs panoramic films. Angle Orthod. 2011;71(3):185-9.

34. Sameshima GT, Sinclair PM. Predicting and preventing root resorption: Part I. Diagnostic factors. Am J Orthod Dentofacial Orthop. 2001;119(5):505-10.

35. Sameshima GT, Sinclair PM. Predicting and preventing root resorption: Part II. Treatment factors. Am J Orthod Dentofacial Orthop. 2001;119(5): 511-5.

36. Silva Filho OG, Berreta EC, Cavassan AO, Capelozza Filho L. Estimativa da reabsorção radicular em 50 anos casos ortodônticos bem finalizados. Ortodontia. 1993;26(1):24-35.

37. Taner T, Ciğer S, Sençift Y. Evaluation of apical root resorption following extraction therapy in subjects with Class I and Class II malocclusions. Eur J Orthod. 1999:21(5):491-6 